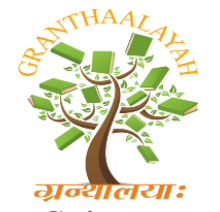

Science

\section{INTERNATIONAL JOURNAL OF RESEARCH - GRANTHAALAYAH A knowledge Repository}

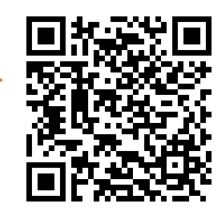

\title{
COMPARATIVE STUDY ON ANXIETY LEVEL BETWEEN BOYS AND GIRLS FOOTBALL PLAYERS
}

\author{
Dr Maibam Chourjit Singh ${ }^{* 1}$, R. K. Nongdren Singh² \\ ${ }^{*}$ Assistant Professor, Department of Physical Education and Sports Science, Manipur University \\ ${ }^{2}$ Research Scholar, Department of Physical Education and Sports Science, Manipur University
}

\begin{abstract}
The purpose of the present study was to find out the anxiety level between boys and girls football players. 60 football players (30 boys and 30 girls) were selected from Subroto Mukherjee football tournament 2015 held at Khuman Lampak Sports Complex for the study. The average age of the players is 16.5 years. The sample of the study has been selected randomly. Hypotheses of the present study were Sports Competitive Anxiety Scores of Boys and Girls football players would be high and there will be no significant difference on Sports Competitive Anxiety Scores between boys and girls football players. Sports competitive Anxiety Test (SCAT) by (Martens et al., 1990) was used to measure the level of anxiety for the football players. The Sports Competitive Anxiety Scores of Boys and Girls football players was found to be average $(n=60$, mean=198.58, $\sigma=2.92$ and SEM =0.37). Difference on Sports Competitive Anxiety Scores between Boys (n=30, mean=18.46, $\sigma=2.30)$ and Girls $(n=30$, mean=18.70, $\sigma=3.47)$ football players was found to be statistically not significant at $p \leq 0.05$ ( $t$-value $=0.760)$ at $d f=78$. The current study was limited in sample size, tools adopted, and variables undertaken for the study. Further research can be done with larger sample size and also on different age group.
\end{abstract}

Keywords:

Anxiety, Boys, Girls, Football, SCAT.

Cite This Article: Dr Maibam Chourjit Singh, and R. K. Nongdren Singh, "COMPARATIVE STUDY ON ANXIETY LEVEL BETWEEN BOYS AND GIRLS FOOTBALL PLAYERS” International Journal of Research - Granthaalayah, Vol. 3, No. 9(2015): 96-100.

\section{INTRODUCTION}

In the games and sports, psychological and physiological factors play an important role in determining the performance level (Grange \& Kerr, 2010; Schilling \& Hyashi, 2001). It has been recognized for many years that psychological factors, in particular anxiety, play an important role in competition. (Lizuka, 2005) observed as a result of his study that many factors, such as expectations, perfectionism, fear of failure, lack of confidence include feelings of anxiety in athletes. Those athletes, who experience high levels of anxiety, may fall sick, muscle tension, show aggressive behaviours face sleeping problems, low self- confidence and drop out of sport (Cox, 2010; Weinberg \& Gould, 2010; Abel \& Larkin, 1990). 
Anxiety which is seen as an important determinant of performance in sports environments has been defined in many ways by authors. As to Anshel "Anxiety is a perceived threat". It is seen in two forms. The first one is trait anxiety which is a part of behavioural patterns of individuals. The latter is state anxiety. Anxiety before or during athletic competitions can hinder your performance as an athlete. The coordinated movement required by athletic events becomes increasingly difficult when your body is in a tense state. A certain level of physical arousal is helpful and prepares us for competition. But when the physical symptoms of anxiety are too great, they may seriously interfere with your ability to compete. Similarly, a certain amount of worry about how you perform can be helpful in competition, but severe cognitive symptoms of anxiety such as negative thought patterns and expectations of failure can bring about a self- fulfilling prophecy. If there is a substantial difference between how you perform during competitions, anxiety may be affecting your performance (Nileshkumar, 2012). Anxiety may be positive motivation force or it may interfere with successful athletic performances. As a positive motivating force it can be instrumental in motivating the athlete to work harder to find new and better ways to improve performances and to help set goals. The athletic skills and his self-confidence as a negative motivator anxiety may interfere with productive as well as constructive thinking. Athletes may attempt to handle anxiety by denying the need to work hard. This can lead to development of poor work habits or athletic technique. These often lead to failure and, in turn, lack of confidence and increased anxiety.

Competitive Anxiety in Sport concludes with a theory of competitive anxiety based on an interaction between uncertainty about the outcome and the importance assigned to that outcome. Anxiety before or during athletic competitions can hinder performance of an athlete. The coordinated movement required by athletic events becomes increasingly difficult when your body is in a tense state. A certain level of physical arousal is helpful and prepares us for competition. But when the physical symptoms of anxiety are too great, they may seriously interfere with your ability to compete. Similarly, a certain amount of worry about how you perform can be helpful in competition, but severe cognitive symptoms of anxiety such as negative thought patterns and expectations of failure can bring about a self-fulfilling prophecy. If there is a substantial difference between how you perform during practice and how you do during competitions, anxiety may be affecting your performance. (Khan and Khan, 2014)

The title of the problem for the present study is stated as "Comparative Study on Anxiety Level between Boys and Girls Football Players"

The objectives of the present study was to find out the sports competitive anxiety test scores of Boys and Girls football players and to find out if there exists any difference on the sports competitive anxiety test scores between Boys and Girls Football players.

The following hypotheses was framed for the present study

Hypothesis 1: The Sports Competitive Anxiety Scores of Boys and Girls football players would be high.

Hypothesis 2: there will be no significant difference on Sports Competitive Anxiety Scores between Boys and Girls Football Players. 


\section{METHODS}

\section{SELECTION OF SUBJECTS}

For the purpose of the study, 60 football players (30 boys and 30 girls) who took part in Subroto Mukherjee football tournament for under 17 boys and girls held at Khuman Lampak Sports Complex from $13^{\text {th }}$ to $19^{\text {th }}$ June 2015 were selected randomly from the participating teams. The average age of the participants was 16.5 years.

\section{SELECTION OF TOOLS}

Sports competitive Anxiety Test (SCAT) by (Martens et al., 1990) was used to measure the level of anxiety for the football players. This test is composed of 15 items on 3-point scale which include 5 spurious items, 8 positive items and 2 negative items. And, as such the maximum possible score on the SCAT was 30. The summated scores on each items on the scale formed the Sports Competitive Anxiety Test scores. Norms for interpretation of the results has been shown below:

\begin{tabular}{|l|l|}
\hline SCAT Score & Verbal Interpretation \\
\hline Less than 17 & Low level of Sports Competitive Anxiety \\
\hline 17 to 24 & Average level of Sports Competitive Anxiety \\
\hline More than 24 & High level of Sports Competitive Anxiety \\
\hline
\end{tabular}

\section{DATA COLLECTION}

The data were collected from the players during the competition before collection of data proper instruction was given to them so that accurate response can be obtain from them.

\section{STATISTICAL TOOLS}

Statistical tools such as mean, standard deviation, standard error of mean, and t-test has been employed in the present study. The level of significance chosen was .05.

\section{RESULTS AND DISCUSSION}

Hypothesis 1: The Sports Competitive Anxiety Scores of Boys and Girls football players would be high.

Table 1: SCAT Scores of Boys and Girls Football players

\begin{tabular}{|l|l|l|l|}
\hline $\mathbf{N}$ & Mean & Standard Deviation $(\boldsymbol{\sigma})$ & Standard Error of Mean \\
\hline 60 & 18.58 & 2.92 & 0.37 \\
\hline
\end{tabular}

The Sports Competitive Anxiety Scores of Boys and Girls football players was found to be average $\left(\mathrm{n}=60\right.$, mean=198.58, $\sigma=2.92$ and $\left.\mathrm{SE}_{\mathrm{M}}=0.37\right)$. It was anticipated that the Sports Competitive Anxiety Scores would be high.

Thus, the hypothesis that "The Sports Competitive Anxiety Scores of Boys and Girls football players would be high" fails to be accepted.

Hypothesis 2: There will be no significant difference on Sports Competitive Anxiety Scores between Boys and Girls football Players. 
Table 2: Mean values and comparison of Sports Competitive Anxiety between Boys and Girls Football Players

\begin{tabular}{|l|l|l|l|l|l|l|}
\hline Sex & N & Mean & $\boldsymbol{\sigma}$ & SEm & df & t- value \\
\hline Boys & 30 & 18.46 & 2.30 & 0.42 & 58 & 0.760 \\
\hline Girls & 30 & 18.70 & 3.47 & 0.63 & & \\
\hline
\end{tabular}

Difference on Sports Competitive Anxiety Scores between Boys $(n=30$, mean=18.46, $\sigma=2.30)$ and Girls $(n=30$, mean $=18.70, \sigma=3.47)$ football players was found to be statistically not significant at $\mathrm{p} \leq 0.05 \mathrm{t}$-value $=0.760$ at $\mathrm{df}=78$.

Thus, the hypothesis "There is no significant difference on Sports Competitive Anxiety Scores between Boys and Girls football players" was accepted.

Mean scores of Anxiety between Boys and Girls are depicted graphically in fig 1.

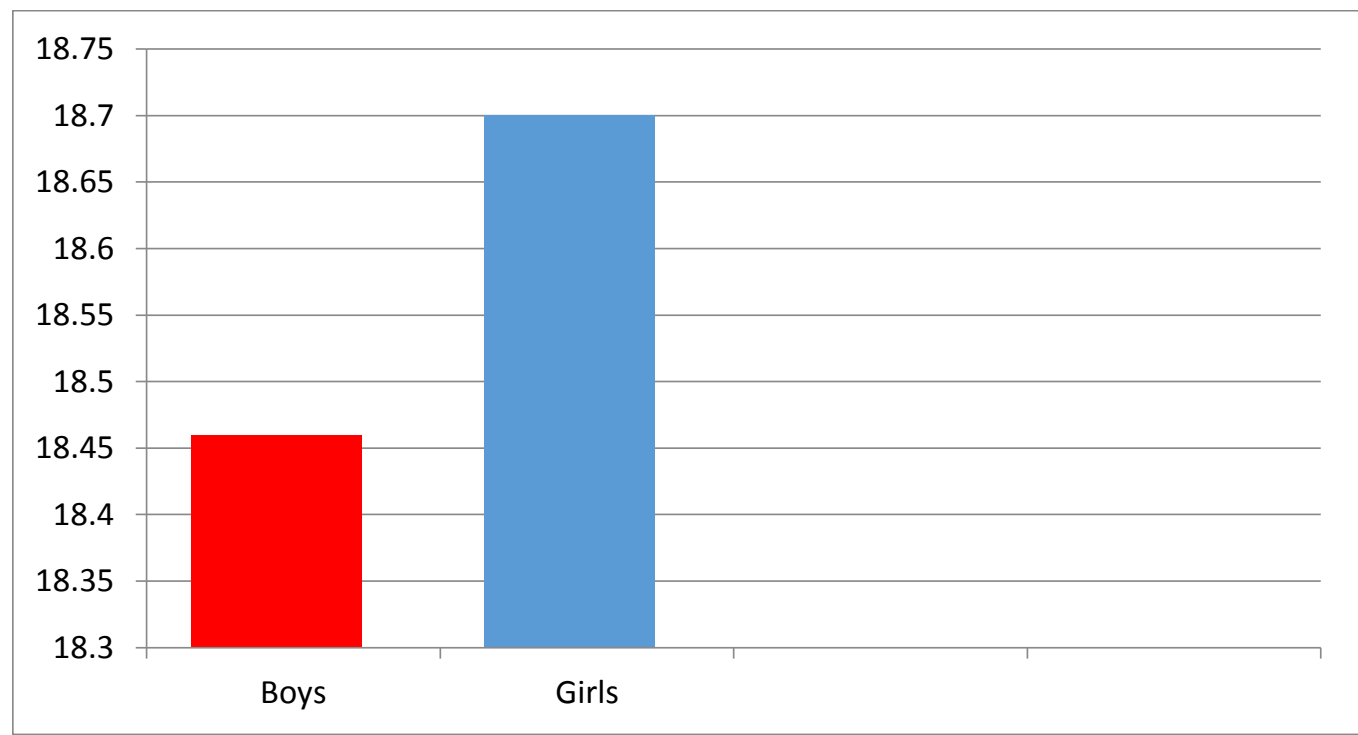

Figure 1: The Graphical Representation of Mean Scores of Anxiety between Boys and Girls Football Players

The study revealed that boys and girls football players have average level of anxiety and there exist no significant difference between boys and girls football players on anxiety.Similar findings were also reported by some studies e. g. Amit K. Gamit (2013), M.N. Singh et al., (2013). The finding of the present study was found to be refuting with some others studies e.g. Quadri Syed Javed (2013) who found that girls players have more anxiety level than boys players.

It may therefore be construed that the Sports Competitive Anxiety of boys and girls football players was average and sex may not be a determining variable for Sports Competitive Anxiety.

\section{CONCLUSION}

The finding of the study reveals that Sports Competitive Anxiety of boys and girls football players was average and there exists no significant difference on SCAT Score between Boys and Girls football players. 


\section{REFERENCES}

[1] Encyclopaedia of Sports and Science and Medicine, Ed; 1971, "Individual

[2] Adjustment to Social Practices and Characteristics".

[3] Grange, P., and Kerr, J. H. (2010). "Physical aggression in Australian football: A qualitative study of elite athletes". Psychology of Sport and Exercise, 11, 36-43.

[4] Schilling, T. A. and Hayashi, C. T. (2001). "Achievement motivation among high school basketball and cross-country athletes: a personal investment perspective", Journal of Applied Sport Psychology 13 (2001), pp. 103-128.

[5] Anshel M.H. Sport psychology: from theory to practice. 3rd ed. Scottsdale, Arizona: Gorsuch Scarisbrick. 115-151 (1997).

[6] Najmuddin Khan and Shahnawaz Khan (2014), "Comparative Study of Sports Competitive Anxiety and Sports Achievement Motivation between Basketball Players and All India Intervarsite Running Events Athletes", Vol-I, Issue- 49, April 2014, http:// reviewofprogress.org/DOI: 10.9780/2321-3485/132201374, ISSN: 2321-3485

[7] Nileshkumar K. Meswania (2012), "A Study of Anxiety Level in Selected Players of Various Schools Sports and Non- Players", Global Research Analysis, Vol-1, Issue: 4, Sept. 2012.

[8] Lizuka (2005), "Anxiety and Performance in Young Tennis Players", Sports Sciences Research 26 (3), pp 73-75

[9] Cox, R.H. (2010), Sport Psychology, concepts and applications. New York: McGraw-Hill.

[10] Weinberg, R.S. \& Gould, D. (2010), Foundations of Sport and Exercise Psychology, Champaign, IL: Human Kinetics.

[11] M N Singh et al., (2013), "A Comparative Study of Sports Competitive Anxiety between Male and Female Inter- Collegiate Badminton Players of Manipur", Indian Streams Research Journal, Volume-3, Issue: 9, Oct. 2013

[12] Abel, J.L. \& Larkin, K.T. (1990). "Anticipation of performance among musicians: Psychology arousal confidence and state anxiety". Psychology of Music, 18, pp. 171-182

[13] Amit K. Gamit (2013), "A Comparative Study of Sports Competitive Anxiety between Male and Female Cricket Players of Gujarat", Indian Journal of Applied Research, Volume-3, Issue: 2, Feb. 2013

[14] Quadri Syed Javed (2013), "A Study of Self Concept and Anxiety among Boys and Girls School Players”, Research Directions, Volume- 1, Issue: 3, Sept. 2013 